DOCÊNCIA UNIVERSITÁRIA

A DISTÂNCIA: UM ESTUDO

SOBRE O PROCESSO DE

ENSINO-APRENDIZAGEM NA

MODALIDADE SEMIPRESENCIAL

\author{
Walteno Martins Parreira Júnior 1 \\ Silvana Malusá ${ }^{2}$ \\ Guilherme Saramargo de Oliveira ${ }^{3}$
}

Resumo

Este trabalho apresenta os resultados de uma pesquisa sobre docência universitária a distância, em cursos de formação de professores que adotam a modalidade semipresencial. Teve como objetivo compreender como ocorre o olhar do professor universitário sobre sua prática pedagógica. Utilizou-se como instrumento de pesquisa um questionário, construído nas abordagens quanti e qualitativa, composto por três partes: identificação/qualificação docente, conteúdo programático e questôes abertas. Os docentes atuam em dois cursos de uma Instituição do Ensino Superior do Triângulo Mineiro, Minas Gerais Ele foi aprovado sob o

1 Walteno Martins Parreira Júnior - Mestre em Educação pela Universidade Federal de Uberlândia - UFU. Professor da Universidade do Estado de Minas Gerais/UEMG - Unidade Ituiutaba. Membro do grupo de pesquisa "Desenvolvimento profissional e docência universitária: saberes e práticas educativas" do Programa de Pós-Graduação.

E-mail: waltenomartins@yahoo.com

2 Silvana Malusá - Doutora em Educação pela Universidade Metodista de Piracicaba - Unimep. Professora da Faculdade de Educação da UFU, coordenadora do grupo de pesquisa "Desenvolvimento profissional e docência universitária: saberes e práticas educativas” PPGEd-UFU.

E-mail: malusa@faced.ufu.br

3 Guilherme Saramago de Oliveira - Doutor em Educação pela UFU, professor da Faculdade de Educação da UFU, membro do grupo de pesquisa "Desenvolvimento profissional e docência universitária: saberes e práticas educativas" do PPGEd-UFU.

E-mail: gsoliveira@ufu.br. 
no 638/11 do Comitê de Ética e Pesquisa da Universidade Federal de Uberlândia - UFU. Os docentes pertencem a dois cursos de uma Instituição de Ensino Superior - IES do Estado de Minas Gerais. Os resultados constataram que os profissionais pesquisados fazem uso das Tecnologias de Informação e Comunicação - TICs - no processo de ensino-aprendizagem para a interaçáo, organização, desenvolvimento dos conteúdos disciplinares e atividades de avaliação.

Palavras-chave: Docência universitária a distância; Prática didático-pedagógica; Ensino semipresencial.

Abstract This paper presents the results of an investigation into the university pedagogical practices of professors who adopt the semipresential modality in education teaching courses. Aimed to understand how this professional looks upon his own practice As a survey instrument, it was used a questionnaire, built on quantitative and qualitative approaches, consisting of three parts: identification / teaching qualification, syllabus and open questions. He was approved under no. 638/11 the Ethics and Research Committee of the Federal University of Uberlândia UFU. The teachers belong in two courses of a Higher Education Institution in Minas Gerais State. The results showed that these professionals make use of Information and Communication Technologies -ICTs - in the process of teaching and learning, for interaction, organization, development of syllabuses and evaluating activities.

Educ. foco,

Keywords: University distance teaching; Didactic and pedagogical practice; Semipresential teaching. 
DOCÊNCIA UNIVERSITÁRIA

A DISTÂNCIA: UM ESTUDO

SOBRE O PROCESSO DE

\section{ENSINO-APRENDIZAGEM NA}

MODALIDADE SEMIPRESENCIAL

\section{INTRODUÇÃO}

Este trabalho tem como finalidade apresentar os resultados de pesquisa desenvolvida com um grupo de professores cujo tema é a docência universitária a distância e a prática do docente que atua com disciplina semipresencial e a distância em cursos de graduação de formação de professores na modalidade presencial. O objetivo é compreender, através de entrevistas com os docentes que atuam nesses cursos, qual o olhar sobre a própria prática didático-pedagógica, com ênfase no material instrucional utilizado. Espera-se chegar a um entendimento mais completo sobre como o docente faz uso das TICs no processo ensino-aprendizagem e entender a relação dele com esses recursos na prática cotidiana da sala de aula virtual.

$$
\begin{aligned}
& \text { É recomendável que as instituiçóes elaborem } \\
& \text { seus materiais para uso a distância, buscando } \\
& \text { integrar as diferentes mídias, explorando a } \\
& \text { convergência e integração entre materiais } \\
& \text { impressos, radiofônicos, televisivos, } \\
& \text { de informática, de videoconferências e } \\
& \text { teleconferências, dentre outros, sempre na } \\
& \text { perspectiva da construção do conhecimento } \\
& \text { e favorecendo a interaçáo entre os múltiplos } \\
& \text { atores. (BRASIL, 2007, p.15) }
\end{aligned}
$$

O professor universitário é desafiado, cotidianamente, pela rapidez com que os recursos tecnológicos evoluem e permitem novas formas de acesso à informaçáo e de (n) 
comunicação. Esse avanço nas TICs exige do docente um esforço para compreender as oportunidades desses instrumentos, assim como o funcionamento deles. Com a disponibilidade dos recursos digitais, novas oportunidades para o cotidiano da educação a distância podem ser utilizadas na interação professor-aluno.

Atualmente, a maioria dos estudantes possuem acesso às TICs e estão habituados a utilizá-las para se comunicar ou informar. Considerando que esse é um dado irreversível, observa-se que são os docentes que necessitam de capacitação e incentivo para a utilizaçáo desses recursos em sala de aula. Tanto é que muitas escolas já utilizam blogs, vídeos, hiperlinks, chats e e-mails, entre outros, e exigem, cada vez mais, a qualificação de seus professores nesse sentido para que complementem as atividades cotidianas das disciplinas que lecionam, sejam elas presenciais ou a distância.

Este trabalho é desenvolvido como uma pesquisa aplicada, exploratória, de abordagem quanti e qualitativa e do tipo estudo de caso. Essa definiçáo foi adotada devido à natureza do objeto de pesquisa ser as práticas didáticas de um grupo de professores de curso de graduação presencial em uma IES onde lecionam disciplinas semipresenciais.

O ensino semipresencial também é conhecido como ensino híbrido ou misto, porque abarca uma miríade de possibilidades: múltiplas combinaçôes de abordagens e de métodos conforme as necessidades, circunstâncias e metas, uso de práticas comumente vistas em educação a distância (recursos multimídia, streaming vídeo, comunicação síncrona e assíncrona, etc.), comunidades de aprendizagem, etc. (QUEVEDO, 2011, p.18)

Para Goldenberg (1997, p.62), a utilização de diferentes abordagens de pesquisa contribui para a análise de diversas questóes, ou seja, "o conjunto de diferentes pontos de vista, e diferentes maneiras de coletar e analisar dados (qualitativa e 
quantitativamente), que permitem uma idéia (sic) mais ampla e inteligível da complexidade de um problema”.

A maior parte dos pesquisadores em ciências sociais admite, atualmente, que não há uma única técnica, um único meio válido de coletar os dados em todas as pesquisas. Acreditam que há uma interdependência entre os aspectos quantificáveis e a vivência da realidade objetiva no cotidiano. (GOLDENBERG, 1997, p.62)

Na instituição escolhida para este estudo há 33 docentes atuando nos cursos de Pedagogia e Química. Desse total, foram selecionados, para a aplicação do instrumento de pesquisa, 13 docentes responsáveis por ministrarem as disciplinas oferecidas no regime semipresencial.

Esses cursos são ofertados no período noturno e em regime anual. $\mathrm{O}$ aluno frequenta a maioria das disciplinas presencialmente e, em cada série, há duas ou três delas que são ministradas na modalidade semipresencial. Esse modelo educacional está contemplado na Portaria Ministerial 4.059/2004, onde define que cursos já reconhecidos podem ofertar até $20 \%$ de sua carga horária a distância. Essas disciplinas são desenvolvidas de forma que parte da carga horária delas é ministrada presencialmente e a outra parte de $33 \%$ até $75 \%$ - a distância.

$\mathrm{O}$ instrumento de pesquisa foi aprovado pelo Comitê de Ética em Pesquisas com Seres Humanos da UFU conforme parecer no. 638/11 dessa instituição. Está dividido em três partes distintas. A primeira, denominada de "Dados gerais sobre o sujeito pesquisado", contém um conjunto de informaçóes sobre a sua caracterização. A segunda, denominada "Categorias a serem estudadas", foi estruturada a partir de quatro categorias selecionadas no documento intitulado "Referenciais de qualidade para educação superior a distância”, que foi publicado pelo Ministério da Educaçáo - MEC. 
As categorias são empregadas para se estabelecer classificações. Nesse sentido, trabalhar com elas significa agrupar elementos, idéias (sic) ou expressões em torno de um conceito capaz de abranger tudo isso. Esse tipo de procedimento, de um modo geral, pode ser utilizado em qualquer tipo de análise em pesquisa qualitativa. (GOMES, 1994, p.70)

Todas as categorias apresentam sete frases afirmativas, às quais são atribuídos valores, por parte de cada sujeito participante, dentro da escala Likert de cinco pontos. Neste trabalho está sendo abordada a categoria "o material instrucional utilizado".

\section{A DOCÊNCIA UNIVERSITÁRIA}

A docência universitária é exercida por um bacharel ou licenciado na área de conhecimento da disciplina que ministra e tem preocupado os especialistas há algum tempo. Segundo Malusá e Silva (2007, p.207), a formação de docentes para o ensino superior não está regulamentada de forma específica, requerendo apenas que seja preparada em cursos de pósgraduação.

Escreve Cicillini (2010, p.30) que o desenvolvimento profissional do docente universitário ocorre em um processo dialético e dialógico, que faz com que o profissional tenha uma relação reflexiva com suas açóes pedagógicas cotidianas, suas ações com relação aos colegas, por meio da troca de informaçôes e experiências, e sua produção de conhecimentos.

Segundo Delors e demais autores (1998, p.152), a contribuição dos professores para o desenvolvimento das sociedades no século XXI será crucial, com a finalidade de preparar os jovens para encarar o futuro com confiança e também de maneira responsável. Assim, os professores têm papel determinante na formação do aluno e com as atitudes dele perante aos estudos, devendo despertar-lhe a curiosidade, 
a autonomia, o rigor intelectual, além de criar-lhe as condiçóes para o sucesso da educação formal e permanente.

$\mathrm{O}$ trabalho do professor náo consiste simplesmente na transmissão de informações ou conhecimentos, mas sim de apresentá-los na forma de problemas, situando-os em um contexto e na perspectiva com a qual o aluno possa estabelecer a ligação entre a solução deles e de outras situaçóes análogas (DELORS et al.,1998, p.157).

Segundo Nóvoa (2008, p.229), o trabalho docente depende da participação do discente, posto que ninguém ensina a quem náo quer aprender.Ele complementa afirmando que "o problema se torna mais complicado se considerarmos as circunstâncias da presença do aluno, que não é produto de um ato de vontade, mas antes, de uma obrigação social e familiar”. Nóvoa (2008, p.232), citando Labaree (2000), escreve ainda que o "bom docente é aquele que se torna nãoindispensável (sic)", que faz com que seus alunos aprendam de forma autônoma, sem a sua ajuda.

Lessard e Tardif (2008, p.268) defendem que as TICs são inevitáveis e os docentes devem aprender a utilizá-las para fins pedagógicos e, assim, transformar o papel deles, deslocandose da transmissáo dos conhecimentos para a de facilitador da assimilação e a incorporação por parte dos alunos que são, cada vez mais, competentes para realizar tarefas e aprendizagens complexas de maneira autônoma.

Com o advento do computador, uma série de novidades e de oportunidades surgiu com a possibilidade de se fazer mais rápido e mais fácil. Porém, durante anos, continuou "sendo utilizado mais como uma ferramenta de apoio ao professor e ao aluno. As atividades principais ainda estavam focadas na fala do professor e na relaçáo com os textos escritos" (MORAN, 2004).

Segundo Valente (1993), a função da escola não deve ser a de ensinar o aluno, mas sim a de criar condiçóes de aprendizagem para o educando. $E$ isso significa que o
Docência Universitária

a Distância: Um Estudo sobre o Processo de

Ensino-Aprendizagem

na Modalidade

Semipresencia 
professor precisa mudar de atitude, deixar de ser o repassador de conhecimento e assumir o papel de desenvolvedor de ambientes de aprendizagem e de facilitador do processo de desenvolvimento intelectual do aluno.

Educar em ambientes virtuais exige mais dedicaçấo do professor, mais apoio de uma equipe técnico-pedagógica, mais tempo de preparação - ao menos nesta primeira fase - e principalmente de acompanhamento, mas para os alunos há um ganho grande de personalização da aprendizagem, de adaptação ao seu ritmo de vida, principalmente na fase adulta. (MORAN, 2003, p.5)

Diante desse contexto de transformação e de novas exigências em relação ao aprender, as mudanças prementes não dizem respeito à adoção de métodos diversificados, mas sim à atitude diante do conhecimento e da aprendizagem, bem como a uma nova concepçáo de homem, de mundo e de sociedade. Isso implica que o professor terá papéis diferentes a desempenhar, fazendo-se necessários novos modos de formação que possam prepará-lo para o uso pedagógico do computador.

A entrada de novas tecnologias no ambiente escolar traz uma nova dimensão à práxis educacional. Isso porque a sociedade atual, também chamada de Sociedade da Informação, sofre mudanças radicais nas relaçóes econômicas, políticas, sociais e culturais. Neste contexto, o processo educacional tenta fazer uma ponte entre o modelo tradicional das escolas regulares, que passa por transformaçóes, e esse grande avanço da tecnologia. (BARROS, 2009, p.2)

Usar o computador como uma ferramenta de apoio no processo ensino-aprendizagem é transformar a relação já existente entre educador e aluno, permitindo o uso de TICs, tanto em sala de aula tradicional quanto nas atividades de 
pesquisa e complementação dos estudos fora dela, estimulando o discente a buscar novas informaçóes e a construir o seu próprio conhecimento.

O resultado é um modelo educacional que pode ser eficiente, em que o professor torna-se um orientador no processo ensino-aprendizagem do aluno. Em outras palavras, o mestre, detentor do saber, deixa de existir, dando lugar a um companheiro de novas descobertas, significando dar ao aluno a direção da própria aprendizagem. (SANTARELLI; SANTANNA, 1998)

Castells (2000, p.108-109) faz referências a características importantes para o entendimento do paradigma das TICs com relação à capacidade de transformação social que elas têm. A primeira característica éque as informaçôes são matérias-primas, "são tecnologias para agir sobre a informação", diferentemente de outras revoluçóes tecnológicas que ocorreram. A segunda característica é referente "à penetrabilidade dos efeitos das novas tecnologias", que vão moldar os processos de existências individuais e coletivas, interagindo através do novo meio tecnológico. O terceiro aspecto é relativo à lógica de redes, onde qualquer sistema ou conjunto de relaçóes usando as novas tecnologias de informação permite a flexibilidade na comunicação, viabilizando um crescimento da rede em detrimento de elementos que estão fora dela.

Por último, Castells (2000, p.109) faz referência à crescente convergência de tecnologias específicas que possibilitam a influência de um sistema altamente integrado nos sistemas de informaçáo na vida em sociedade. As tecnologias de transmissão e conexão das telecomunicaçôes são apenas uma forma de processamento da informação e estão, cada vez mais, diversificadas e integradas em redes operadas por computadores.

Para o professor que assume a docência ensinando a distância, além dos conhecimentos científicos e didáticos, 
é também necessário que tenha o domínio de recursos tecnológicos que são indispensáveis para o seu cotidiano.

Para compreender o papel do professor, pode-se considerar os parâmetros de referência de qualidade definidos pelo MEC. Segundo eles, os professores devem ser capazes de desenvolver um conjunto de açóes:

a) Estabelecer os fundamentos teóricos do projeto;

b) Selecionar e preparar todo o conteúdo curricular articulado a procedimentos e atividades pedagógicas;

c) Identificar os objetivos referentes a competências cognitivas, habilidades e atitudes;

d) Definir bibliografia, videografia, iconografia, audiografia, tanto básicas quanto complementares;

e) Elaborar o material didático para programas a distância;

f) Realizar a gestáo acadêmica do processo de ensinoaprendizagem, em particular motivar, orientar, acompanhar e avaliar os estudantes;

g) Avaliar-se continuamente como profissional participante do coletivo de um projeto de ensino superior a distância (BRASIL, 2007, p.20).

De acordo com os referenciais de qualidade apresentados pelo MEC como competências que os professores devem ter para exercer a atividade a distância (BRASIL, 2007) e também com os propostos por Castells (2000) para o uso das TICs na sociedade moderna, pode-se observar que o uso das tecnologias deve seguir um planejamento apropriado, interdisciplinar juntamente com as habilidades e competências dos professores - para estimular os alunos a empregá-las na construção do seu conhecimento.

Ressalta-se que no processo de ensino e aprendizagem, desenvolvido por meio de Ambientes Virtuais de Aprendizagem - AVAs, é necessária a participação efetiva de todos os atores por meio do compartilhamento de experiências, pesquisas e descobertas. Nesse modelo, o professor é o mediador da aprendizagem e responsável pelo planejamento, desenvolvendo açóes e atividades que sejam interessantes e desafiadoras, mas 
também de acordo com o perfil e nível intelectual dos alunos (KENSKI et al., 2009, p.224).

Aliar a utilização das TICs às salas de aulas de cursos presenciais é um dos objetivos da proposta de utilização dos $20 \%$ a distância em cursos semipresenciais, para estimular a autonomia do aluno e também os recursos digitais.

$\mathrm{Na}$ modalidade semipresencial, estudantes e professores estáo separados fisicamente em determinados momentos da disciplina, mas interligados por meio das tecnologias de comunicação e interaçáo e dos materiais didáticos empregados. Por tais especificidades, a semipresencialidade tornase um elemento a mais de flexibilizaçáo curricular, no que diz respeito às condiçôes individuais de cada estudante, ao ritmo de aprendizagem, ao local e ao tempo de dedicação aos estudos. (MARCHI, ARAÚJO; ISTREIT, 2008, p.2)

Uma preocupação a mais é a transição de um curso da modalidade presencial para um modelo híbrido, no qual a maioria das disciplinas continua naquela modalidade e algumas vão passar para o modelo semipresencial. Determinante saber como será conduzida essa alteração no modelo e de que modo essas disciplinas serão ofertadas.

Muitas organizaçóes estão se limitando a transpor para o virtual adaptaçóes do ensino presencial (aula multiplicada ou disponibilizada). Há um predomínio de interação virtual fria (formulários, rotinas, provas, e-mail) e alguma interaçáo on-line (pessoas conectadas ao mesmo tempo, em lugares diferentes). Os cursos são muito empacotados, seguem fórmulas semelhantes, dáo ênfase excessiva ao conteúdo e pouca à aprendizagem em pequenos grupos, à pesquisa significativa, à produção de conhecimento adaptado à realidade de cada aluno e grupo. (MORAN, 2003, p.8) 
Para a produçáo de um material instrucional com qualidade técnica e didática é necessário: “ [...] o mesmo cuidado com que o professor planeja a sua aula e seleciona os textos e autores mais adequados, também deve selecionar os programas e vídeos apropriados" (MALUSÁ, 2003, p.147). A autora complementa citando Kenski (1996), que alerta para que o professor tenha o cuidado de não usar esses recursos meramente como ferramentas auxiliares, que vão funcionar autonomamente. É preciso que os alunos estejam informados sobre os aspectos e o contexto do que se está trabalhando em sala de aula (2003, p.148). Como se observa nos parâmetros de qualidade do MEC:

A produção de material impresso, vídeos, programas televisivos e radiofônicos, videoconferências, CD-Rom, páginas web, objetos de aprendizagem e outros, para uso a distância, atende a diferentes lógicas de concepção, produção, linguagem, estudo e controle de tempo. Para atingir estes objetivos, é necessário que os docentes responsáveis pela produção dos conteúdos trabalhem integrados a uma equipe multidisciplinar, contendo profissionais especialistas em desenho instrucional, diagramação, ilustração, desenvolvimento de páginas web, entre outros. (BRASIL, 2007, p.13-14)

As disciplinas oferecidas na modalidade semipresencial se distinguem por serem organizadas em estrutura modular de ensino e aprendizagem, focada na aprendizagem autônoma do aluno, por se utilizarem da mediação de recursos didáticos organizados em diferentes suportes tecnológicos e por dependerem de esforço para serem desenvolvidas. Elas exigem um planejamento cuidadoso e a organizaçáo de um cronograma detalhado, considerando as aulas presenciais e a distância.

Diante do exposto, observa-se que a profissáo docente é complexa e exigente na forma de atuar e se capacitar. 
Com o desenvolvimento das tecnologias da informaçáo e comunicação, deve ser constante e necessário o esforço para se manter atualizado no domínio e na utilização pedagógica dos recursos digitais.

\section{RESULTADOS E DISCUSSÓES}

Dos treze instrumentos de pesquisa distribuídos, dez foram preenchidos e devolvidos, ou seja, 76,9\% dos sujeitos responderam às indagaçóes. Tem-se que do curso de Química todos os cinco questionários foram respondidos; e dos oito distribuídos no curso de Pedagogia, apenas cinco docentes os responderam.

$\mathrm{Na}$ primeira parte do instrumento de pesquisa é realizada a identificação e caracterização dos respondentes. São sete sujeitos do sexo feminino e três do masculino. Esse dado comprova a tendência, nos cursos de formação de professores, de haver maior número de docentes do sexo feminino. Isso está provavelmente ligado à questão histórica de que o magistério foi atribuição das mulheres e ainda hoje é visto dessa forma por muitas pessoas.

Quanto à titulação dos docentes, $10 \%$ possuem o título de Doutor, $40 \%$ possuem o título de Mestre e os outros 50\% possuem especializaçáo. De acordo com $70 \%$ dos docentes, a opção pelas especializaçóes foi para servir de aperfeiçoamento pessoal e 30\% foram diretamente focadas para o mestrado.

Quanto à faixa etária, $50 \%$ dos pesquisados estão acima de 50 anos, 20\% têm entre 41 a 50, 30\% entre 31 a 40 e nenhum dos docentes está na faixa inicial de 21 a 30 anos.

Quanto ao tempo de docência universitária, 40\% dos entrevistados possuem mais de 20 anos, seguidos de $30 \%$ que têm de 11 a 20, outros $20 \%$ têm entre cinco e 10 anos e $10 \%$ contam menos de cinco anos de exercício no magistério superior.

Os participantes da pesquisa são experientes e isso pode facilitar a atuação deles em sala de aula, mas a utilização das

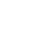

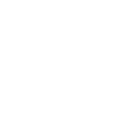$$
\text { s. }
$$ 
TICs nas disciplinas semipresenciais pode ser um problema, uma vez que não tiveram preparação específica na formação inicial. Segundo Zabalza (2004, p.141), o domínio e o exercício da profissão são adquiridos ao longo do tempo e não ocorre por transferência da sabedoria divina.

Esses saberes provêm de fontes diversas (formaçáo inicial e continuada dos professores, currículo e socialização escolar, conhecimento das disciplinas a serem ministradas, experiência na profissáo, cultura pessoal e profissional, aprendizagem com seus pares etc.). (TARDIF; RAYMOND, 2000, p.212)

Outra informação adquirida com o instrumento de pesquisa é que a maioria (70\%) dos professores participou de cursos de capacitação para a utilização de ferramentas digitais; $20 \%$ não responderam e $10 \%$ que não participaram. A capacitação deles deve ser abrangente, preparando-os para a utilização de recursos tecnológicos que se compóem de vídeos, sons, fóruns, entre outros, além de um ambiente virtual de aprendizagem para ser utilizado como concentrador das açóes da disciplina e do curso.

Quanto à capacitação para a utilização de ambientes e técnicas de educação a distância, 60\% afirmaram que foram capacitados e $20 \%$ que não foram, enquanto outros $20 \%$ não responderam. Deve-se ressaltar que essa capacitação é uma etapa importante para a preparação dos docentes que vão atuar nas disciplinas a distância.

É necessário que os professores busquem uma formação para o uso das tecnologias sendo que tal formação deve favorecer ao entendimento de que as TICs podem proporcionar valiosas possibilidades de ensino, aprendizagem, pesquisa, promoção e divulgação de conhecimentos. Ou seja, somente a justaposiçáo das tecnologias no fazer pedagógico não basta, é necessário 
que se mudem as metodologias de ensino. (FELDKERCHER, 2010, p.8)

Essa opiniáo é compartilhada com outros autores que acreditam na necessidade de atualização do docente para utilizar esses recursos no cotidiano da aula a distância.

Uma outra atividade importante nesse
momento é a capacitaçáo para o uso das
tecnologias necessárias para acompanhar o
curso em seus momentos virtuais: conhecer
a plataforma virtual, as ferramentas, como se
coloca material, como se enviam atividades,
como se participa num fórum, num chat,
tirar dúvidas técnicas. (MORAN, 2004,
p.249)

Segundo Francisco e Machado (2006, p.6), na elaboração de cursos em Educação a Distância - EAD é necessário oferecer suporte aos professores envolvidos. Esse suporte passa pelo treinamento em tecnologia e na metodologia do curso, assessoria para a produçáo de materiais e acesso a ferramentas apropriadas e também no reconhecimento financeiro el ou acadêmico do trabalho em EAD. E, no caso analisado, a maioria dos respondentes afirmou que participaram de cursos de formação para atuarem em EAD.

\section{[...] as TICs parecem completamente inevitáveis e os docentes devem aprender a utilizá-las para fins pedagógicos. Elas podem transformar o papel do docente, deslocando o seu centro da transmissão dos conhecimentos para a assimilação e a incorporação destes pelos alunos, cada vez mais competentes para realizar de maneira autônoma tarefas e aprendizagens complexas. (TARDIF; LESSARD, 2008, p.269)}

A parte dois do instrumento de pesquisa está dividida em quatro categorias e cada uma delas está subdividida em sete itens. Neste trabalho, será analisada apenas uma categoria. Cada item dela apresenta uma afirmação e foi solicitado ao
Docência Universitária a Distância: Um Estudo sobre o Processo de Ensino-Aprendizagem na Modalidade Semipresencial 
respondente que valorasse a fase, considerando uma escala de um a cinco, em que o numeral um significa "Nada importante", o dois "Pouco importante", o três indica "neutro", o quatro "Importante" e o número cinco da escala equivale a "Muito importante". Deve-se considerar que algumas frases não foram valoradas em alguns questionários, possivelmente porque $\mathrm{o}$ docente não tem uma opiniáo formada sobre o tema em pauta ou não quer se posicionar.

Para a análise da categoria Qualidade do material didático institucional, as frases selecionadas estão relacionadas com o planejamento e produção do material didático utilizado no processo ensino-aprendizagem, considerando a organização, preparação e apresentação do conteúdo programático por parte do professor para que o aluno possa participar de suas aulas a distância.

Entre os diversos componentes do sistema de EAD, sempre foi considerado de importância fundamental o material didático, produzido especificamente para quem estuda sem contar com o apoio presencial de um professor. Por isso, a equipe de produção de material didático assume papel único e específico no processo de ensinar. [...] Porém, é importante salientar que, ao falarmos de material didático, estamos nos referindo a uma diversidade de meios tecnológicos que podem ser utilizados no processo de ensinar, com o objetivo de propiciar aprendizagem por parte do estudante. Portanto, não se restringe ao texto didático impresso. (PRETI, 2010, p.14-15)

Chaves (1998, p.33) escreve que as TICs revolucionaram as tecnologias utilizadas, tornando possível transformar as "palavras faladas, palavras escritas e impressas, outros sons, gráficos, desenhos, imagens estáticas e em movimento” em arquivos digitais. Ele explica que:

Com o computador, surgiu multimídia: um megameio de comunicaçáo que incorpora, 
em um mesmo ambiente, todos os meios de comunicação anteriores. Em seu sentido mais lato, o termo "multimídia" se refere à apresentação ou recuperação de informaçóes que se faz, com o auxílio do computador, de maneira multissensorial, integrada, intuitiva e interativa. (CHAVES, 1998, p.33)

Para ele, é possível utilizar esses recursos para transformar dados em informaçáo da forma mais adequada, "de modo a garantir a facilidade do uso, a eficácia da apresentação ou recuperação da informação, a efetividade da sua compreensáo e a eficiência de todo o processo" (CHAVES, 1998, p.34).

Considerando os referenciais de qualidade do MEC, deve-se observar suas recomendaçóes quanto à produção $\mathrm{e}$ utilizaçấo de material instrucional:

$$
\begin{aligned}
& \text { [...] é recomendável que as instituições } \\
& \text { elaborem seus materiais para uso a distância, } \\
& \text { buscando integrar as diferentes mídias, } \\
& \text { explorando a convergência e integração entre } \\
& \text { materiais impressos, radiofônicos, televisivos, } \\
& \text { de informática, de videoconferências e } \\
& \text { teleconferências, dentre outros, sempre na } \\
& \text { perspectiva da construção do conhecimento } \\
& \text { e favorecendo a interação entre os múltiplos } \\
& \text { atores. (BRASIL, 2007, p.14) }
\end{aligned}
$$

Para a frase 1, Usar material didático impresso, $40 \%$ dos respondentes consideraram-na muito importante, $20 \%$ que é importante, outros $20 \%$ pouco importante, $10 \%$ se manifestaram de forma neutra e $10 \%$ não avaliaram a frase. Assim, os resultados anotados apontam que $60 \%$ dos respondentes consideraram importante ou muito importante sua utilização, o que pode significar que ainda há uma preponderância desse tipo de material sobre o digital. Conforme apresenta Preti, "escrever um texto didático significa comunicar, socializar conhecimentos, estabelecer interaçáo com o leitor/ estudante, ainda mais na $\mathrm{EAD}$, em que os interlocutores estáo distantes no tempo e no espaço" (2010, p.20).

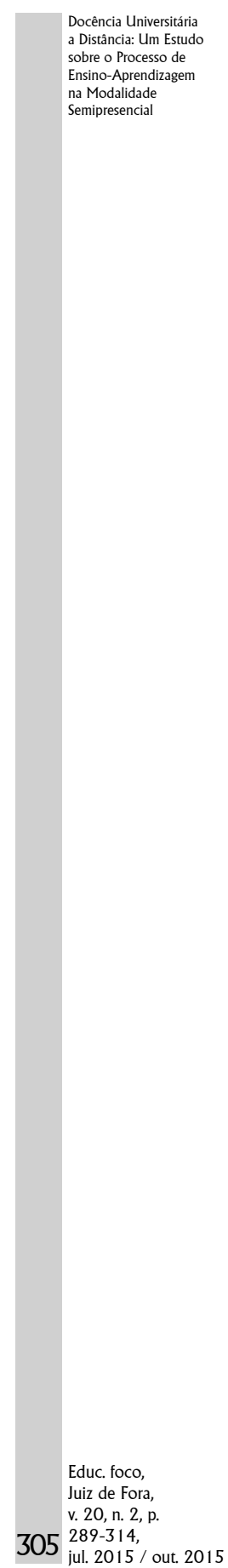


A frase 2, Usar outros materiais didáticos (sites, vídeos, áudios, etc.), foi considerada por $50 \%$ dos docentes como muito importante e a outra parte a considerou importante, enquanto as outras valoraçóes não foram consideradas. Podese observar que a maioria dos respondentes está de acordo com Kenski (2005, p.7), que escreve que a utilização de AVAs possibilita o uso concomitante de vários recursos, tais como vídeos, textos, animaçóes e até a própria imagem, tanto de alunos como de professores.

A frase 3, Usar a internet como recurso para transmissão de conhecimentos, foi considerada como importante por $50 \%$ dos respondentes, para $40 \%$ como muito importante e $10 \%$ não responderam. Logo, sendo considerada por $90 \%$ dos respondentes como importante ou muito importante, tal situação está de acordo com a pesquisa bibliográfica e também com os documentos oficiais que indicam ser essa a oportunidade para a oferta de informaçóes e assistência ao aluno, tanto para transmissão de conteúdo como para o atendimento a dúvidas e questionamentos.

A frase 4, Planejar e organizar os conteúdos disciplinares para posteriormente produzir o material instrucional, 70\% dos docentes consideram-na muito importante, 30\% como importante e as outras opções não foram escolhidas. Os dados mostram que $100 \%$ dos docentes consideram muito importante ou importante e esse resultado está de acordo com a literatura pesquisada e com as respostas anteriores da categoria. Considerando que os sujeitos utilizam recursos tecnológicos diferentes para a apresentação do conteúdo é necessário que ocorra um planejamento e a escolha de qual deles empregar em cada situação.

A produção do material instrucional a ser utilizado pelo professor deve ser planejada em conformidade com o projeto pedagógico do curso, buscando-se atingir os objetivos propostos. até a elaboração do material didático e das atividades teórico/práticas que o compóe 
deve relacionar-se para que o conteúdo seja apresentado ao aluno de forma que o mesmo consiga atingir os seus objetivos. Partindo dessa visão, incentiva-se que o professor construa o seu material, levando em consideração normas e padróes, e respeitando a lei de Direitos Autorais Lei $\mathrm{n}^{\circ}$. 9.610, de 19 de fevereiro de 1998. (BERTAGNOLLI et al., 2008, p.4)

Observando a frase 5, Transformar o material utilizado em sala de aula presencial em documento digital, vê-se que 50\% dos respondentes consideram importante a transformação, $40 \%$ muito importante e $10 \%$ não responderam. Observase que $90 \%$ dos respondentes consideram importante ou muito importante a transposição do material. Esse resultado é condizente com Neves e Medeiros (2006, p.41), pois, segundo as autoras, para o profissional da educação no século XXI, será necessário ter as competências de produzir em diferentes linguagens e mídias, principalmente em quatro áreas básicas, “material impresso, TV/vídeo, rádio e informática/rede".

Isto exposto, ainda é importante fazer uma observação mais cuidadosa das respostas apresentadas, pois ocorre, em muitas situaçóes, uma simples transposição do texto escrito para o texto digital sem o tratamento imprescindível de observação da qualidade necessária para que ocorra o aproveitamento pelo aluno.

A frase 6, O material instrucional deve promover a autonomia do aluno, é considerada muito importante para $80 \%$ dos sujeitos, para $20 \%$ é importante e as outras opçóes não foram consideradas. Essa frase é considerada importante ou muito importante por todos os docentes, portanto pode-se concluir que os sujeitos da pesquisa estáo preocupados com a autonomia dos discentes quanto aos estudos e a aquisiçáo do conhecimento, considerando as dificuldades de se estudar sozinho e sem o apoio imediato do professor.

Essa autonomia preconizada pelos sujeitos da pesquisa é apresentada por Carmona (2008, p.7-8), para quem há 
um sentimento de que na EAD e com o uso das TICs há o desenvolvimento da autonomia do estudante por meio da educação. Ele complementa que:

En diferentes análisis que se han realizado acerca de la educación virtual, es común encontrar la concepción de que una de las características de esta, es la posibilidad que brinda a los sujetos participantes del proceso de desarrollar capacidades de autonomía. (CARMONA, 2008, p.8)

Para a frase 7, O material instrucional deve ser revisto periodicamente, pode-se observar que $50 \%$ dos respondentes consideram importante a revisão do material utilizado e que outros $40 \%$ acreditam que é muito importante e somente $10 \%$ avaliaram a questáo como neutra. Pode-se observar, portanto, que $90 \%$ dos respondentes consideram importante ou muito importante a revisão do material utilizado.

É uma das funçôes do professor a observação da aceitação e das condiçóes de atualidade de seus materiais instrucionais e fazer as correçóes necessárias, tanto de um ano para o outro como ao longo da disciplina. Deve o docente ficar atento aos sinais de falta de entendimento ou de pouca compreensão por parte do aluno quando da exposiçáo da matéria e buscar formas alternativas de apresentação dos temas.

Um bom curso de educação a distância procura ter um planejamento bem elaborado, mas sem rigidez excessiva. Permite menos improvisaçóes do que uma aula presencial, mas também deve evitar a execução totalmente hermética, sem possibilidade de mudanças, sem prever a interação dos alunos. Precisamos aprender a equilibrar o planejamento e a flexibilidade (que está ligada ao conceito de liberdade, de criatividade). Nem planejamento fechado, nem criatividade desorganizada, que vira só improvisação. (MORAN, p.147) 
Escreve Malusá (2003, p.165) que a atividade docente necessita de aperfeiçoamento contínuo para atender o desenvolvimento dos conhecimentos científico e cultural. Por essa razão, segundo ela, há necessidade de se repensar a prática docente a cada período letivo para que os processos de ensino e aprendizagem ocorram de forma atualizada. Os respondentes, em sua maioria, também concordam que o material a ser utilizado necessita ser atualizado com periodicidade para se manter condizente com os conhecimentos científicos e tecnológicos.

Após a exposição e interpretação das frases da categoria, nota-se que há uma escolha predominante para a opçáo muito importante na escala de valoraçáa, bem como uma segunda opçáo bem considerada e também significativa que é o importante. Há uma única valoraçấo para a opção neutra (frase 1), enquanto dois respondentes consideraram a opçáo pouco importante para a mesma frase. Há que considerar que um sujeito da pesquisa náo valorou três frases dessa categoria, possivelmente por não ter uma opiniáo formada sobre o tema ou náo querer se posicionar sobre o assunto.

Um bom curso é mais do que conteúdo, é pesquisa, troca, produção conjunta. Para suprir a menor disponibilidade ao vivo do professor, é importante ter materiais mais elaborados, mais autoexplicativos, com mais desdobramentos (links, textos de apoio, glossário, atividades [...]. (MORAN, p.147)

Segundo Maia e Mattar (2007, p.71), há uma alteração na metodologia pedagógica na transposiçáo da disciplina presencial para a disciplina a distância, pois pelo fato de "ser discursiva e baseada na exposição oral do professor presencial, a metodologia de $\mathrm{EAD}$, fundada em novas mídias, propóe recursos de interatividade, colaboraçáa, troca e cooperaçáo por meio de um ambiente [virtual]". E é o que se percebe da análise das respostas apresentadas pelos docentes, que 
confirmam a utilização de recursos digitais e novas mídias para a apresentação e discussáo do conteúdo programático.

\section{CONSIDERAÇÓES FINAIS}

Considerando-se os dados coletados com o instrumento de pesquisa, pode-se observar que na categoria Usar material didático impresso os docentes avaliados apontam na direção da plena utilizaçáo das TICs, pois valoraram as frases de forma positiva, considerando-as como importante ou muito importante na maioria dos casos.

Transformar um curso presencial em semipresencial é uma ação que deve ser planejada e que requer uma dedicação de todo o grupo, desde a coordenação e docentes até os técnicos e a administração, pois há muitas alterações a serem desenvolvidas para atender aos requisitos definidos na legislação.

Os professores consideram a utilização de vários recursos pedagógicos, além do tradicional texto, declarando - em suas respostas afirmativas - que estão aproveitando alguns recursos tecnológicos em suas aulas. Logo, ocorreu uma transposição do material antes utilizado em sala de aula para novas plataformas tecnológicas.

Este trabalho pode contribuir com a discussão, posicionando que a apresentação de um assunto de forma presencial náo pode ser explorada da mesma forma que na modalidade a distância. Sua transposição para o virtual necessita de um planejamento cuidadoso, observados os objetivos pedagógicos a serem alcançados, a disponibilidade de recursos tecnológicos e a capacidade dos alunos de terem acesso técnico e cultural ao produto disponibilizado. Pode-se apoiar em Kenski (2005, p.2), o qual escreve que a exploração didática de um mesmo assunto precisa sofrer alteraçóes para usufruir dos diversos suportes tecnológicos disponíveis.

Para a melhoria da qualidade da aula, seja presencial ou a distância, é necessário um conjunto de açóes que passam 
pela formação inicial e continuada dos docentes, oferta de recursos tecnológicos para a construção de suas aulas, apoio institucional por parte da coordenação e direção da escola, remuneração digna dos profissionais da educação e também pelo reconhecimento do esforço desprendido pelo docente na elaboração, aplicação e correção das atividades, bem como o atendimento virtual aos alunos. Conforme escrevem Delors e demais autores (1998, p.153), para melhorar a qualidade da educaçáo, antes de tudo, deve-se melhorar o recrutamento, a formação, o estatuto social e as condiçóes de trabalho dos professores para que possam corresponder com suas qualidades, conhecimentos, competências e motivação.

É consenso que o planejamento e a execução das disciplinas remodeladas de presencial para a distância necessitam de novos parâmetros bem mais complexos do que a simples transposição da prática anteriormente utilizada para o ambiente digital, sendo necessária uma nova preparação, com novos conceitos. Quanto a isso, escreve Quevedo (2011, p.18) que a recriaçáo das atividades da educaçáo presencial para o formato eletrônico ou a utilização dos princípios de aprendizagem que produziram bons resultados no passado não garante o sucesso quando de sua aplicação imediata na aula digital.

\section{REFERÊNCIAS}

BARROS, S. O uso da tecnologia no cotidiano escolar. In: TEIXEIRA, G. F. M. e MIRANDA, A. A. B. (Org.). Seminário nacional uno e o diverso na educação escolar, 10., Uberlândia: Anais. Edufu, 2009. CD-ROM.

BERTAGNOLLI, S. de C. et al. Potencialidades e desafios da modalidade semipresencial. Renote, Revista novas tecnologias na educação. Porto Alegre, v.6, n.1, jul. 2008. Cinted-UFRGS. ISSN: 1679-1916.

BRASIL. Referenciais de qualidade para educação superior a distância. Diário Oficial [da] Republica Federativa do Brasil. Brasília, DF, 2007.
Docência Universitária

a Distância: Um Estudo

sobre o Processo de

Ensino-Aprendizagem

na Modalidade 
CARMONA, H. E. C. Consideraciones acerca de la educación virtual como comunidad de relaciones afectivo-valorativas. Revista Iberoamericana de Educación. V. 46 n. 7. 25 Jul. 2008.

CASTELLS, M. A sociedade em rede. V.1, 8 ed. Editora Paz e Terra. 2000.

CHAVES, E. O. C. Tecnologia e educação: o futuro da escola na sociedade da informação. Campinas: Midware Editora, 1998, 194 p. DELORS, J. et al. Educação: um tesouro a descobrir. São Paulo: Cortez; Brasília: Unesco. 1998.

FELDKERCHER, N. Formação de professores para o uso das tecnologias da informação e comunicação. In: DALBEN, A. I. L. F. et al. (Org.). Encontro nacional de didática e prática de ensino (Endipe), 15. Belo Horizonte. Anais. UFMG, 2010, CD-ROM.

FRANCISCO, D. J.; MACHADO, G. J. C. Sociedade, EAD, inclusão e formação de professores. Revista Iberoamericana de Educacion. Madrid, v. 38, n. 1, 25 fev. 2006.

GOLDENBERG, M. A arte de pesquisar: como fazer pesquisa quantitativa em ciências sociais. Rio de Janeiro: Record. 1997.

GOMES, R.. A análise de dados em pesquisa qualitativa. In: MINAYO, M. C. S. (Org.). Pesquisa social: teoria, método e criatividade. Petrópolis: Vozes. 1994. P.67-80.

KENSKI, V. M. et al. Ensinar e aprender em ambientes virtuais. Educação temática digital. Campinas, v. 10, n. 2, p. 223-249. Jun. 2009.

KENSKI, V. M. Gestão e uso das mídias em projetos de educação a distância. Revista e-curriculum, São Paulo, v.1, n.1, Dez. 2005/ Jul. 2006.

LESSARD, C.; TARDIF, M. As transformaçóes atuais do ensino: três cenários possíveis na evolução da profissão de professor? In: TARDIF, M.; LESSARD, C. (Org.). O ofício de professor: história, perspectivas e desafios internacionais. Petrópolis: Vozes, 2008. P. 255-277.

LITWIN, E. Educação a distância: temas para o debate de uma nova agenda educativa. Porto Alegre: Artmed. 2001.

MAIA, C.; MATTAR, J. $A B C$ da EAD. São Paulo: Pearson Prentice Hall, 2007.

MALUSÁ, S. Investigação sobre a atualização docente no ensino 
superior. In: MALUSÁ, S.; FELTRAN, R. C. S. (Org.) A prática da docência universitária. São Paulo: Factash Editora, p.137-174. 2003.

MALUSÁ, S. ; SILVA, V. A. Saberes e formação pedagógica: pensando a prática da docência universitária. In: FONSECA, S. G. (Org.). Currículos, saberes e culturas escolares. Campinas: Alínea, 2007. p.207-225.

MARCHI, A. C. B.; ARAÚJO, D. D.; ISTREIT, I. R. (2008). Modalidade semipresencial de ensino: alguns resultados da implantação em disciplinas de graduação da UPF. Revista novas tecnologias na educação. Porto Alegre, v.6, n.2, Dez. 2008. Cinted-UFRGS.

MORAN, J. M. Os novos espaços de atuação do educador com as tecnologias. In: ROMANOWSKI, J. P. et al (Org.). Conhecimento local e conhecimento universal: diversidade, midias e tecnologias na educação. V.2, Curitiba: Champagnat, 2004, p.245-253.

MORAN, J. M. Educação inovadora presencial e a distância. 2003. Disponível em: <http://www.eca.usp.br/prof/moran/inov_1.htm>, acesso em: set. 2008.

MORAN, J. M.; ARAÚJO FILHO, M.; SIDERICOUDES, O. $A$ ampliação dos vinte por cento a distância: estudo de caso da Faculdade Sumaré-SP. Disponível em; <http://www.abed.org.br/congresso2005/por/pdf/172tcc3.pdf>, acesso em jan. 2007]

NEVES, C.; MEDEIROS, L. Mídias na educação. In: BRASIL. Ministério da Educação. Secretaria de Educação a Distância. Desafos da educação a distância na formação de professores. Brasília: Seed, 2006.

NÓVOA, A. Os professores e o novo espaço público da educação. In:TARDIF, M.; LESSARD, C. (Org.). O ofício de professor: história, perspectivas e desafios internacionais. Petrópolis: Editora Vozes, 2008, p. 217-233.

PRETI, O. Produção de material didático impresso: orientaçóes técnicas e pedagógicas. Cuiabá: UAB/UFMT, 2010. 210 p.

QUEVEDO, A. O ensino semipresencial, do ponto de vista do aluno. E-curriculum, São Paulo, v.7, n.1, Abr. 2011. Disponível em $<$ http://revistas.pucsp.br/index.php/curriculum>, acesso em jul. 2011. 
SANTARELLI, D.; SANTANNA, S. Feitos e efeitos: Informática na Escola. São Paulo - SP, Berkeley Brasil, 1998.

TARDIF, M.; RAYMOND, D. Saberes, tempo e aprendizagem do trabalho no magistério. Educação \& Sociedade [on-line]. V.21, n.73, dez. 2000, p.209-244.

VALENTE, J. A. Diferentes usos do computador na educação, In: VALENTE, J. A. (Org.), Computadores e conhecimento: repensando a educação. Campinas - SP, Gráfica central da Unicamp, Disponível em: <http://pan.nied.unicamp.br/publicacoes/publicacao_detalhes. php?id=19>, Acesso em: jul. 2009.

ZABALZA, M. A. O ensino universitário: seu cenário e seus protagonistas. Porto Alegre: Artmed, 2004.

Data de recebimento: junho de 2012

Data de aceite: julho de 2014 